\title{
Stability of organic solar cells with PCDTBT donor polymer: An interlaboratory study - ERRATUM
}

\author{
Laura Ciammaruchi, Ricardo Oliveira, Ana Charas, Tulus, Elizabeth von Hauff, Giuseppina Polino, \\ Francesca Brunetti, Rickard Hansson, Ellen Moons, Miron Krassas, George Kakavelakis, \\ Emmanuel Kymakis, José G. Sánchez, Josep Ferre-Borrull, Lluis F. Marsal, Simon Züfle, Daniel Fluhr, \\ Roland Roesch, Tobias Faber, Ulrich S. Schubert, Harald Hoppe, Klaas Bakker, Sjoerd Veenstra, \\ Gloria Zanotti, Eugene A. Katz, Pälvi Apilo, Beatriz Romero, Tülay Aslı Tumay, Elif Parlak, \\ Luciano Mule Stagno, Vida Turkovic, Horst-Günter Rubahn, Morten Madsen, Vaidotas Kažukauskas, \\ David M. Tanenbaum, Santhosh Shanmugam, and Yulia Galagan
}

doi: 10.1557/jmr.2018.163, Published by Materials Research Society with Cambridge University Press, 21 June 2018.

In Ciammaruchi et al., ${ }^{1}$ the affiliation of Vida Turkovic, Horst-Günter Rubahn, and Morten Madsen was erroneously changed during revision. The correct affiliation is as follows:

Vida Turkovic, Horst-Günter Rubahn, and Morten Madsen.

SDU NanoSYD, Mads Clausen Institute, University of Southern Denmark, Sønderborg 6400, Denmark.

The publisher regrets this error.

\section{REFERENCE}

1. L. Ciammaruchi, R. Oliveira, A. Charas, Tulus, E. von Hauff, G. Polino, F. Brunetti, R. Hansson, E. Moons, M. Krassas, G. Kakavelakis, E. Kymakis, J.G. Sánchez, J. Ferre-Borrull, L.F. Marsal, S. Züfle, D. Fluhr, R. Roesch, T. Faber, U.S. Schubert, H. Hoppe, K. Bakker, S. Veenstra, G. Zanotti, E.A. Katz, P. Apilo, B. Romero, T.A. Tumay, E. Parlak, L. Mule Stagno, V. Turkovic, H-G. Rubahn, M. Madsen, V. Kažukauskas, D.M. Tanenbaum, S. Shanmugam, and Y. Galagan: Stability of organic solar cells with PCDTBT donor polymer: An interlaboratory study. J. Mater. Res. 33, 1909 (2018). 